\title{
BMJ Open Feasibility of using an Early Warning Score for preterm or low birthweight infants in a low-resource setting: results of a mixed-methods study at a national referral hospital in Kenya
}

\author{
Eleanor J Mitchell (D , ${ }^{1}$ Zahida P Qureshi, ${ }^{2}$ Fredrick Were, ${ }^{3}$ Jane Daniels, ${ }^{1}$ \\ George Gwako, ${ }^{2}$ Alfred Osoti, ${ }^{2}$ Jacqueline Opira, ${ }^{4}$ Lucy Bradshaw, ${ }^{1}$ Mary Oliver, ${ }^{5}$ \\ Phoebe Pallotti, ${ }^{6}$ Shalini Ojha (D) 7,8
}

To cite: Mitchell EJ, Qureshi ZP, Were $\mathrm{F}$, et al. Feasibility of using an Early Warning Score for preterm or low birthweight infants in a low-resource setting: results of a mixed-methods study at a national referral hospital in Kenya. BMJ Open 2020;10:e039061. doi:10.1136/ bmjopen-2020-039061

- Prepublication history and additional material for this paper are available online. To view these files, please visit the journal online (http://dx.doi. org/10.1136/bmjopen-2020039061).

Received 02 April 2020 Revised 11 September 2020 Accepted 22 September 2020

A) Check for updates

(C) Author(s) (or their employer(s)) 2020. Re-use permitted under CC BY-NC. No commercial re-use. See rights and permissions. Published by BMJ.

For numbered affiliations see end of article.

\section{Correspondence to}

Eleanor J Mitchell;

Eleanor.Mitchell@nottingham. ac.uk

\section{ABSTRACT}

Introduction Fifteen million babies are born prematurely, before 37 weeks gestational age, globally. More than $80 \%$ of these are in sub-Saharan Africa and Asia. 35\% of all deaths in the first month of life are due to prematurity and the neonatal mortality rate is eight times higher in low-income and middle-income countries (LMICs) than in Europe. Early Warning Scores (EWS) are a way of recording vital signs using standardised charts to easily identify adverse clinical signs and escalate care appropriately. A range of EWS have been developed for neonates, though none in LMICs. This paper reports the findings of early work to examine if the use of EWS is feasible in LMICs. Methods We conducted an observational study to understand current practices for monitoring of preterm infants at a large national referral hospital in Nairobi, Kenya. Using hospital records, data were collected over an 8-week period in 2019 on all live born infants born at $<37$ weeks and/or $<2500 \mathrm{~g}(\mathrm{n}=294,255$ mothers $)$ in the first week of life. Using a chart adopted from the EWS developed by the British Association of Perinatal Medicine, we plotted infants' vital signs. In addition, we held group discussions with stakeholders in Kenya to examine opinions on use of EWS.

Results Recording of vital signs was variable; only $63 \%$ of infants had at least one temperature recorded and $53 \%$ had at least one heart rate and respiratory rate recorded. Stakeholders liked the traffic-light system and simplicity of the chart, though recognised challenges, such as staffing levels and ability to print in colour, to its adoption.

Conclusion EWS may standardise documentation and identify infants who are at higher risk of an adverse outcome. However, human and non-human resource issues would need to be explored further before development of an EWS for LMICs.

\section{BACKGROUND}

Globally, 15 million babies are born prematurely $^{1}$; more than $80 \%$ in sub-Saharan Africa (12.3\% of all births). ${ }^{1}$ Mortality for a preterm infant born in a low-income or middle-income

\section{Strengths and limitations of this study}

This is the first study exploring the possibility of using a neonatal early warning score in a low-resource setting.

- The opinions of a wide range of stakeholders, including senior policy-makers and clinicians, are included.

- Detailed data on preterm and low birthweight infants' vital signs were recorded for the first 7 days of life, though was limited to what was routinely recorded.

- The tool includes physiological reference ranges for term and late preterm infants, whereas we studied preterm or low birthweight infants.

- Data collection was limited to a tertiary referral hospital in Nairobi, however, many preterm infants in low-resource settings are cared for in centres with much larger constraints.

country (LMIC) is eight times higher than in Europe. ${ }^{2}$ Among the causes of neonatal mortality (NMR), prematurity remains the biggest killer with $35 \%$ of all neonatal deaths attributed to preterm birth or its complications. ${ }^{3}$ The United Nations Sustainable Development Goals recognise the need to significantly improve outcomes for newborn infants and have a strategic vision to end preventable newborn deaths, with all countries aiming to reduce the NMR to at least 12 per 1000 live births. ${ }^{4}$

In Kenya, where the most recent NMR was 19.6 per 1000 live births, ${ }^{5}$ infants born prematurely should be managed in accordance with national and international guidance for essential newborn care, ${ }^{6-8}$ though this may not always reflect what happens in practice. Guidance includes a range of evidence-based 
recommendations for care in the first week of life, for example, provision of Kangaroo Mother Care (KMC) for all clinically stable infants weighing $<2000 \mathrm{~g}$, which is recommended for hypothermia prevention. ${ }^{689}$ The World Health Organisation (WHO) estimates that $>80 \%$ of moderate to late (32-37 weeks) preterm infants could survive with the provision of essential newborn care. ${ }^{10}$

Early Warning Scores (EWS) are a way of quickly and easily identifying adverse clinical signs and are often used in adult populations in a variety of clinical areas, ${ }^{11}$ however, they are less commonplace for neonatal care. A review by Mortensen et $a l^{12}$ identified seven EWS systems for neonates, including the Newborn Early Warning Trigger and Track (NEWTT) Framework, developed in the UK by the British Association for Perinatal Medicine ${ }^{13}$ for infants primarily on postnatal wards with little or no increased surveillance (online supplemental material 1). While this framework states that the chart should be triggered for 'high-risk' infants, only late preterm infants $\left(34-36^{+6}\right.$ weeks) are considered due to the fact most preterm infants born in the UK at earlier gestations are admitted for higher-dependency neonatal care with continuous monitoring. Infants who could most benefit from closer monitoring and early detection of adverse signs, particularly in low-resource settings where continuous monitoring is not available in neonatal units, are preterm or low birthweight infants. Indeed Mortensen et al's review stated that of the four systems published in full, two only included term babies weighing $>2500 \mathrm{~g}$. The authors concluded that none of the available systems at the time considered 'highrisk' infants who had been admitted for neonatal care and recommended modifications be made to existing systems. For example, the reference ranges included in the NEWTT were based on neonatal physiological parameters in term and late preterm infants and adjustments may need to be made based on gestational age. ${ }^{14}$ To the best of our knowledge, there are no published EWS from low-resource settings such as Kenya nor are such systems currently utilised. All available scoring systems were developed in high-income countries where continuous vital sign monitoring in neonatal units is standard, yet there is evidence, within an obstetric setting, that an EWS system is feasible and possible to implement in a low-resource setting. ${ }^{15}$

In keeping with other EWS systems, the NEWTT adopts a traffic-light scoring system. An infant's vital signs are recorded on to a single page. If a measurement is in the red zone or there are two recordings in the amber zone, the attending nurse is alerted and immediate escalation to a review by a suitably qualified practitioner is required. The purpose of such a strategy is to alert healthcare professionals to the potential of deterioration in the condition of a high-risk infant and give them an opportunity to intervene with appropriate care.

The aim of this study was to investigate whether an EWS system in preterm and low birth weight infants could be implemented in a low-resource setting such as Kenya.

\section{METHODS}

\section{Observational study}

In order to understand the characteristics of infants born in this setting, first we conducted an observational study at the Kenyatta National Hospital (KNH), a tertiary referral hospital, in Nairobi, Kenya. Data were collected during an 8-week period in March to April 2019 from routinely recorded data. No interventions nor study specific actions in response to observations were required and management of the infants followed usual practice. All infants born at $\mathrm{KNH}$, during the study period, who were $<37$ weeks gestational age and/or $<2500 \mathrm{~g}$ at birth were included. Data were collected from birth until day 7 or discharge/death. Outborn infants (not born at KNH and admitted postnatally) were excluded.

Research midwives, trained during a 3-day workshop, collected data using paper data collection booklets. Maternal and infant characteristics were collected and all vital signs recordings (temperature, heart rate and respiratory rate) in the infant's clinical notes were collected. All data were entered into a password-protected studyspecific database (Macro (Elsevier)) by the study coordinator. Data quality checks were undertaken remotely by the UK team. Maternal and infant characteristics were summarised descriptively using the mean, $\mathrm{SD}$, minimum and maximum for continuous variables and frequency counts and percentages for categorical variables along with the number of observations. Analyses were conducted in Stata V.15 (StataCorp). Data on temperature, heart rate and respiratory rate were retrospectively plotted onto graphs representing the NEWTT system, showing values that were within the red, amber and green zones, using the reference ranges specified in the NEWTT.

No informed consent was sought from parents since the study was observational and participants were not subjected to any intervention.

\section{Stakeholder meeting}

In order to understand possible barriers and facilitators to the use of an early warning track and trigger system in Kenya, a stakeholder meeting was held in July 2019 in Nairobi. This was attended by 78 delegates from a range of organisations (online supplemental material 2). Delegates were split into groups of approximately 8-10 and asked to consider and feedback: (1) what they did and did not like about an early warning track and trigger system, (2) what would need to be in place to enable its use and (3) what are the perceived barriers to its use. Feedback was written by groups using flipchart paper and verbal feedback given. A narrative thematic analysis ${ }^{16}$ was conducted and themes were identified from the feedback provided.

\section{Patient and public involvement}

Patients and the public were not involved in the design or conduct of this study. However, non-government organisations and charities representing patients and the public were involved in the stakeholder meeting. 


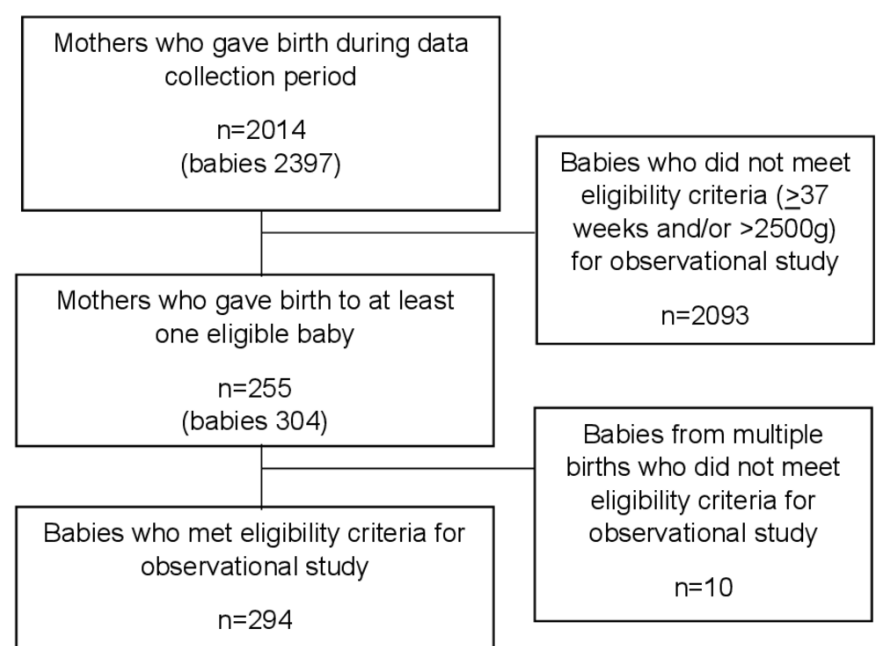

Figure 1 Study flow diagram.

\section{RESULTS \\ Observational study}

Data were collected between 5 March 2019 and 30 April 2019 on the labour suite, postnatal wards and newborn unit of the participating hospital. During the data collection period 2397 infants were born in $\mathrm{KNH}$ (figure 1). 294 infants (255 mothers) (14.6\%) met the eligibility criteria of being born at $<37$ weeks gestation and/or weighing $<2500 \mathrm{~g}$. Ten infants, from multiple births, were subsequently excluded as they did not meet the eligibility criteria. Two hundred and six infants were from singleton pregnancies, 82 from twin pregnancies and 6 from triplet pregnancies.

The mean (SD) age of the mother was 28 (6) years and just under half were educated to secondary/high school level (124/255, 49\%). Infants' characteristics are included in table 1 .

\section{Recording of vital signs (heart rate, respiratory rate, temperature, in clinical records)}

Very few infants had vital signs recorded in the first hour of life (table 1) and $\mathrm{KMC}$ was not recorded as having been initiated in any of the 180 clinically stable infants soon after birth.

The number of recorded observations per infant per day was analysed (table 2). On day 1, less than half of the infants $(136 / 294,46 \%)$ had at least one temperature recording, 130/294 (44\%) had at least one heart rate recording and 129/294 (44\%) had at least one respiratory rate recording. The number of infants with at least one recording in each of the domains increased throughout the hospital admission: on day 7, 86/104 $(83 \%)$ of infants had at least one temperature recording, $85 / 104(82 \%)$ had at least one heart rate recording and $83 / 104(80 \%)$ had at least one respiratory rate recording. This also includes infants who were then discharged on or died on day $7(n=9)$, in addition to the 95 infants who remained in hospital. For these 95, each infant had a mean (SD) of 18 (5.1) temperature recordings, 18 (6.8)
Table 1 Characteristics of infants $<37$ weeks gestational age and/or $<2500 \mathrm{~g}$ at birth born at the Kenyatta National Hospital in March to April 2019

\begin{tabular}{ll}
\hline Characteristic & Total ( $\mathbf{n}=\mathbf{2 9 4})$ \\
\hline Sex: no (\%) of females & $135(54)$ \\
\hline Mode of delivery $-\mathrm{n}(\%)$ & $123(42)$ \\
\hline Vaginal & $3(1)$ \\
\hline Elective caesarean section & $168(57)$ \\
\hline Emergency caesarean section & $0(0)$ \\
\hline Delayed cord clamping ( $\mathrm{n}=14 ; 280$ unknown) & $1977(603)$ \\
\hline Birth weight (g) mean (SD) & $32.6(2)$ \\
\hline Head circumference (cm) ( $\mathrm{n}=19)$ Mean (SD) & $36.0(5)$ \\
\hline Length (cm) ( $\mathrm{n}=4$ ) mean (SD) & \\
\hline Estimated gestational age at birth-n (\%) & $26(9)$ \\
\hline$<28$ weeks & $70(24)$ \\
\hline $28-32+6$ weeks & $123(42)$ \\
\hline $33-36+6$ weeks & $73(25)$ \\
\hline$>37$ weeks & $2(<1)$ \\
\hline Unknown & $14(5)$ \\
\hline Gestational age estimation based upon-n (\%) & $30(10)$ \\
\hline First trimester ultrasound & \\
\hline Clinical assessment & \\
\hline
\end{tabular}

Last menstrual period and/or clinical assessment 242 (82) (mother)

\begin{tabular}{|c|c|}
\hline Dubowitz and New Ballard score & $6(2)$ \\
\hline Unknown & $2(<1)$ \\
\hline $\begin{array}{l}\text { No }(\%) \text { of babies who required resuscitation at } \\
\text { birth }(n=287)\end{array}$ & $110(37)$ \\
\hline \multicolumn{2}{|l|}{$\begin{array}{l}\text { Type of resuscitation }- \text { not mutually exclusive } \\
(n=110)\end{array}$} \\
\hline Stimulation only & $12(11)$ \\
\hline Ventilation & $91(83)$ \\
\hline Continued ventilation & $36(33)$ \\
\hline Advanced resuscitation & $4(4)$ \\
\hline $\begin{array}{l}\text { No }(\%) \text { of babies who received maternal breast } \\
\text { feeding within one hour of birth }(n=260)\end{array}$ & $39(13)$ \\
\hline $\begin{array}{l}\text { No of babies who had initiation of Kangaroo } \\
\text { Mother care soon after birth (stable babies only) } \\
(n=180)\end{array}$ & $0(0)$ \\
\hline
\end{tabular}

No (\%) of babies who had temperature within one $10(3)$ hour of birth*

$\begin{array}{ll}\text { No (\%) of babies who had heart rate at birth* } & 58(20) \\ \begin{array}{l}\text { No (\%) of babies who had respiratory rate at } \\ \text { birth* }\end{array} & 70(24)\end{array}$

${ }^{*}$ Recorded in clinical records.

heart rate recordings and 17 (6.6) respiratory rate recordings throughout their admission.

Over the entire study period, 185/294 (63\%) infants had at least one temperature recorded, 156/294 (53\%) had at least one heart rate recording and 155/294 (53\%) had at least one respiratory rate recording. Retrospectively, each recording for each domain (temperature, heart rate, 
Table 3 Subsequent temperature recordings for 92 infants who had an initial temperature recorded of $<36^{\circ} \mathrm{C}$

\begin{tabular}{lllc}
\hline $\begin{array}{l}\text { Temperature } \\
\left({ }^{\circ} \mathrm{C}\right)\end{array}$ & $\begin{array}{l}<4 \text { hours } \\
(\mathrm{n}=25)(27 \%)\end{array}$ & $\begin{array}{l}4-6 \text { hours } \\
(\mathrm{n}=26)(28 \%)\end{array}$ & $\begin{array}{l}>6 \text { hours } \\
(\mathrm{n}=41) \\
(46 \%)\end{array}$ \\
\hline$<36$ & $10(40 \%)$ & $7(27 \%)$ & $12(29 \%)$ \\
36 to $<36.5$ & $5(20 \%)$ & $5(19 \%)$ & $11(27 \%)$ \\
36.5 to 37.5 & $9(36 \%)$ & $11(42 \%)$ & $15(37 \%)$ \\
$>37$ to 38 & - & $3(12 \%)$ & $3(7 \%)$ \\
$>38$ & $1(4 \%)$ & - & - \\
\hline
\end{tabular}

respiratory rate) was mapped to a single red, amber or green zone on the UK NEWTT by the researchers. These recordings were not charted on the NEWTT in real time by the clinical staff and we did not collect data on what action(s), if any, were taken in response to a red or amber recording. Although, the NEWTT indicates escalation of care for one recording in the red zone or two recordings in the amber zone, we only included single recordings since it was impossible to know whether an action was taken after one single amber recording.

$97 / 185(52.4 \%)$ had at least one temperature recording in the moderate hypothermic range $\left(<36^{\circ} \mathrm{C}\right)$ and $145 / 185$ $(78.4 \%)$ had at least one recording between $36^{\circ} \mathrm{C}$ and $36.49^{\circ} \mathrm{C}$. Of the 97 infants who had a recorded temperature of $<36^{\circ} \mathrm{C}, 92$ had any subsequent temperature recording, almost half $(41 / 92,46 \%)$ of which were taken $>6$ hours later (range $30 \mathrm{~min}$ to 46 hours). Of those, 29 infants' $(32 \%)$ subsequent temperature remained $<36^{\circ} \mathrm{C}$ (table 3).

Tachycardia, defined as a heart rate of $>161$ beats/ minute, was noted in $98 / 156$ infants $(62.8 \%)$, and $34 / 156$ $(21.8 \%)$ had at least one recording $>175$ beats per minute (red zone). High respiratory rate ( $>80$ breaths $/ \mathrm{min}$; red zone) was recorded, at least once, in 24/155 (15.5\%) and $109 / 155(70.3 \%)$ had at least one recording of $61-80 \mathrm{bpm}$ (upper amber zone). A respiratory rate of $<30$ breaths/ min (red zone) was recorded at least once in 9/155 (6\%) and $73 / 155(47 \%)$ had at least one recording of 30-39 breaths/min (lower amber zone). Figure 2 shows recordings for the 95 infants who were still in hospital at day
7 plotted onto colour-coded graphs representing the NEWTT's reference ranges.

\section{Stakeholder meeting}

Seventy eight stakeholders attended the 1-day meeting to discuss the development of this tool in a low-resource setting such as Kenya. Stakeholder types are shown in online supplemental material 2. Feedback groups contained a variety of stakeholder types. The main themes that emerged from stakeholder discussions were (1) simplicity and ease of use of the tool, (2) sustainability and resource and (3) training and implementation. Example quotes are included for each theme.

\section{Simplicity and ease of use}

Stakeholders reported they liked the coloured trafficlight system since this enabled easy interpretation of the data, recognition of need for action and earlier identification of danger signs.

'The colours are good and explains why'.

'It would be easy to identify infants at risk'.

Several stakeholders also commented they liked the combined presentation of several vital signs on one chart, rather than having lots of paper notes which can easily become untidy or misplaced. One policy-maker commented that '[the chart's] simplicity would make universal coverage easier'. Some also considered whether it would be possible to digitise the system, for example, by creating an app, though recognised while this would negate the use for coloured printing, it would not relieve issues with availability of resources.

\section{Sustainability and resources}

Several stakeholders commented that although they liked the traffic-light system approach, it may be difficult to print the document since colour printing is expensive and often not available.

\section{'Printing coloured is a challenge'}

The main concerns for the majority of stakeholders were the availability of healthcare staff to make and document the recordings. It was recognised that such

Table 2 Number of infants with vital signs recordings (temperature, heart rate, respiratory rate) per day for the 7-day data collection period

\begin{tabular}{lllll}
\hline Day & Babies in hospital & $\begin{array}{l}\text { At least one temperature } \\
\text { recording, (\%) }\end{array}$ & $\begin{array}{l}\text { At least one heart rate } \\
\text { recording, (\%) }\end{array}$ & $\begin{array}{l}\text { At least one respiratory } \\
\text { rate recording, (\%) }\end{array}$ \\
\hline 1 & 294 & $136(46)$ & $130(44)$ & $129(44)$ \\
\hline 2 & 272 & $165(61)$ & $139(51)$ & $139(51)$ \\
\hline 3 & 222 & $147(66)$ & $130(59)$ & $128(58)$ \\
\hline 4 & 194 & $127(65)$ & $119(61)$ & $119(61)$ \\
\hline 5 & 139 & $110(79)$ & $107(77)$ & $107(77)$ \\
\hline 6 & 115 & $90(78)$ & $89(77)$ & $90(78)$ \\
\hline 7 & 104 & $86(83)$ & $85(82)$ & $83(80)$ \\
\hline
\end{tabular}



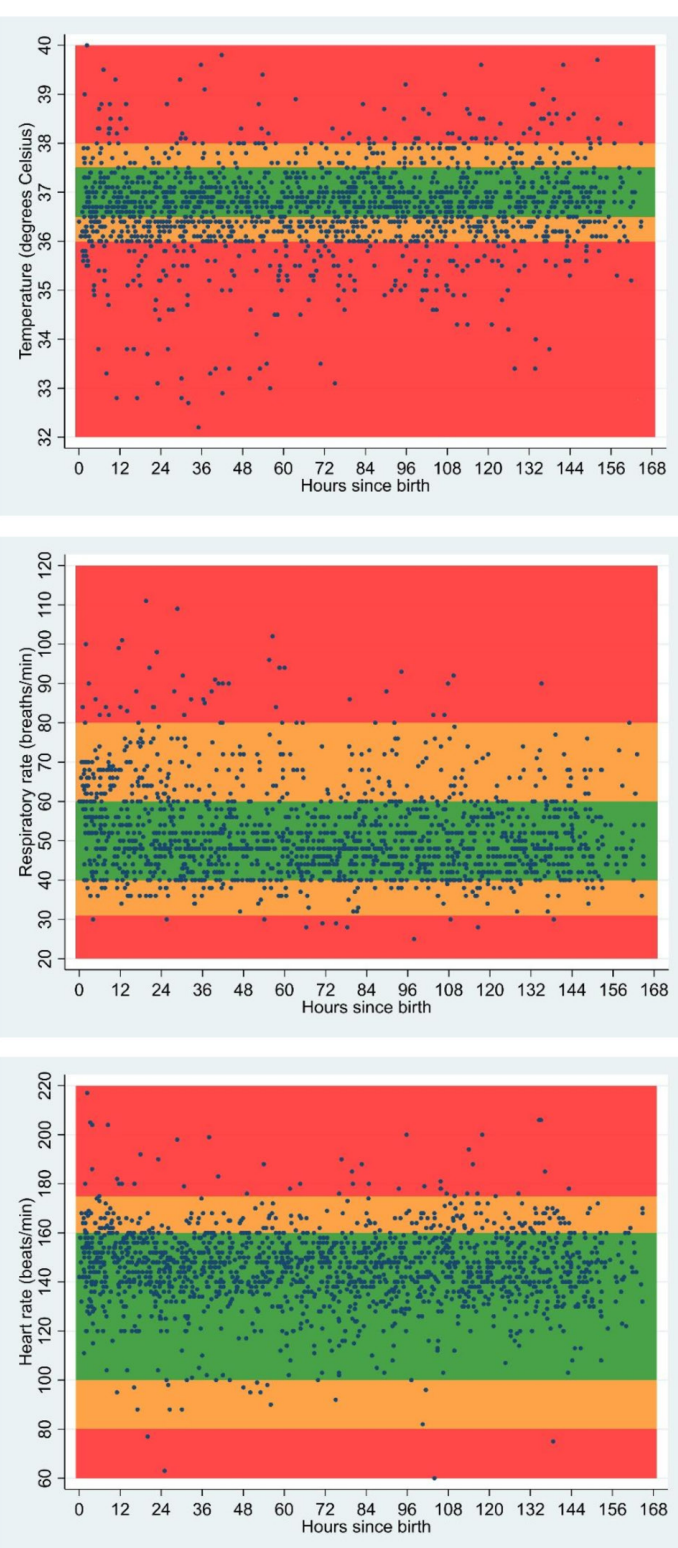

Figure 2 Vital sign recordings of preterm, low birthweight infants born and admitted to a tertiary referral hospital in Kenya for first 7 days of life $(n=95)$ data from infants who were in hospital at day 7. Each dot represents a vital sign recording. Since infants had multiple vital signs recordings during their admission, they could have several values across each of the colour zones at multiple time points. Graph adapted from NEWTT (Newborn Early Warning Trigger and Track).

a system would be acceptable if it replaced the current system of recording vital signs but would not be acceptable as additional workload. Further to this the major barrier to implementation of this or any similar EWS was recognised as the lack of resources, both staff and interventions, to be able appropriately escalate the care of those infants who would be identified as sick. The early warning track and trigger system requires immediate escalation to a more senior neonatologist if a value falls into a red zone or two values in an amber zone; stakeholders felt this may not be possible given staffing levels on neonatal units in this setting.

'We have low staff:patient ratios. This [EWS] has very intense observational needs in a staff-constrained set-up'

\section{Training and implementation}

Some stakeholders felt that staff working on the newborn/ neonatal unit may not like it since it may 'feel like more work' although others recognised that while initial resistance may be encountered this could be overcome by educating staff members of the potential value of such a system. Many stakeholders commented that training on its use would be paramount, which should include not only how to complete the tracking system and trigger escalation, but its potential to reduce neonatal mortality. A nongovernmental organisation representative commented that while implementing such a system may be a good idea, it would 'require national level harmonisation' and that a close working relationship with the Ministry of Health would be important, since it would need to be endorsed at both a national and organisational level.

'It should be integrated into existing tools and the curriculum'.

'Harmonise/integrate this with existing tools to avoid double work'.

\section{DISCUSSION}

This is the first study exploring the possibility of using a neonatal EWS in LMICs. EWSs are recommended for use in routine practice in the $\mathrm{UK}^{13}$ and may have the potential for supporting early recognition of unwell infants. ${ }^{17}$ However, before any practice can be transferred from one healthcare setting to another it is important to test the feasibility of implementing the practice in the target setting. ${ }^{18}$

EWSs are predicated on regular recordings of vital signs. At KNH, local guidelines stipulate newborn infants should have vital signs checked every $4-6$ hours,${ }^{19}$ however, our study demonstrates that the routine recording of vital signs in infants' notes was infrequent; only half had any heart or respiratory rate recordings and around two thirds had any temperature recording during their admission. Indeed even for the infants with a low temperature $\left(<36^{\circ} \mathrm{C}\right)$ that would be in the red zone on an EWS, many of them did not have a subsequent temperature recorded within 4-6 hours. Interestingly, the number of infants with at least one recording increased during their admission. This could be because fewer infants remained in hospital throughout the 7 days and those that remained are more likely to be infants who are unwell and require longer hospital care. It is likely, therefore, that these infants were prioritised by the staff and monitored more closely. The first 24 hours of life for an infant are critical and $25 \%-45 \%$ of all neonatal deaths occur in this 
period $^{20}$; it is of importance, then, that less than half of infants in the observational study had vital signs recorded on day 1 of life and only a very small handful of infants had any vital signs recorded within the first hour of life. These findings are in-keeping with other studies, for example, about $40 \%$ infants had vital signs chart available in the Nairobi Newborn Study, which was a retrospective review of 33 neonatal facilities in Nairobi City County. ${ }^{21}$ In addition, none of the 180 stable infants had KMC initiated shortly after birth, despite clear evidence that KMC, when compared with standard care, reduces neonatal mortality in preterm infants and infants weighing $<2000$ g. ${ }^{22}$ It will be important to ensure that early implementation of KMC is considered in the further development of an EWS in this setting.

Our study included detailed data on preterm and LBW infants' vital signs' recordings, which included temperature, for the first 7 days of life. Keeping newborn infants warm is a key aspect of essential newborn care. ${ }^{23}$ Hypothermia is common in all newborns, particularly preterm and LBW infants, regardless of country of birth. In a large systematic review of neonatal hypothermia ${ }^{24}$ prevalence ranged from $32 \%$ to $85 \%$ in 21 hospital-based studies in Africa and Asia (with the exception of one study which reported $8 \%$ prevalence ${ }^{25}$ ). Temperature data collected in our study is consistent with other studies reporting hypothermia. Infants' temperatures ranged from $32.1^{\circ} \mathrm{C}$ to $40^{\circ} \mathrm{C}$. Of the 2249 recorded temperatures during the 7 -day data collection period, over one-third (859/2249, $38 \%)$ were $<36.4^{\circ} \mathrm{C}$. Almost one-third of infants who had a recorded temperature of $<36^{\circ} \mathrm{C}$, had a subsequent temperature recording of $<36^{\circ} \mathrm{C}$. If infants were more closely monitored and care escalated if a low temperature was identified, for example, by using simple colourcoded chart such as an EWS, it may be possible for action to be taken sooner, thus potentially preventing further hypothermia.

A standardised template, such as an EWS chart, could support better record keeping. Stakeholders identified that the simple traffic-light system could be easily adaptable to local practice. However, concerns about lack of resources weighed heavily in their minds. This included lack of material resources such as inability to print in colour and the larger issue of shortfalls in numbers of healthcare professionals available for newborn care. The lack of adequate resources for neonatal care in Kenya is well documented. ${ }^{21}{ }^{26}$ In such situations, our results show that any new intervention is likely to be useful only if it does not increase the workload of the healthcare staff.

The Nairobi Newborn Study ${ }^{21}$ suggested that implementation of standardised medical and nursing notes could improve care. A priority setting exercise to improve global newborn health recommended that the development of simple clinical algorithms to refer neonates with signs of infection and consequently reduce newborn mortality was a top priority. ${ }^{27}$ Although currently there is no evidence that using neonatal EWS improves outcomes in LMICs, research in closely related clinical areas is encouraging: in Ethiopia, the introduction of a Modified Obstetric Early Warning Score (MOEWS) in a referral hospital, improved practice in several domains. ${ }^{28}$

The desired improvement in outcomes can only be achieved from EWSs if there is an appropriate escalation of care when required. In this study, infants' vital signs were retrospectively plotted to the red and amber zones on the NEWTT, using data available via clinical records. Whether clinical action was taken as a result of an adverse vital sign is unknown since these data were not collected. We are, therefore, only able to report the number of infants who may have hypothetically triggered an escalation of care, by the fact a value was plotted to a single red or amber zone. Since the observational study was undertaken to understand current practice, the NEWTT was applied without any modifications. The physiological parameters used therefore pertain to term or late preterm infants and further work will be required to modify these parameters to be more suitable for use in preterm and low birthweight infants. For example, since respiratory rates and heart rates are likely higher in preterm infants than term or late term infants, the need for escalation of care may be overestimated, using the current unmodified version of the NEWTT.

At the stakeholder meeting, the lack of adequately trained medical and nursing staff was again seen as an impediment to such escalation, particularly if the practice were to be implemented widely. The $\mathrm{KNH}$ is a tertiary referral centre. Most preterm infants in LMICs including within Kenya are cared for in centres with significantly larger constraints than the $\mathrm{KNH}$. In this context, it is worth considering if the use of EWSs may enable staff to identify patients with greater need sooner and hence facilitate more efficient use of limited resources. A suitably adapted neonatal EWS, using physiological parameters relevant to preterm infants, could replace existing documentation systems and may improve the situation by replacing a cumbersome process of documentation with a more streamlined method.

This is the first study investigating the possibility of using a neonatal EWS in LMICs. We used mixed-methods to explore current practice, and report the opinions of a range of relevant stakeholders into understanding the potential use of neonatal EWS in Kenya. However, we recognise our study has some limitations. First, the study was conducted in a large tertiary hospital which is relatively well resourced. As this is an exploratory study, our aim was to scope current practice and explore the possibility of using EWS in KNH before considering the bigger challenge of rolling it to more remote settings. We used the existing NEWTT chart, designed for term and late preterm infants (rather than all preterm infants), to plot vital signs. Outcome data in large datasets are needed to determine whether the thresholds that define the red and amber zones are applicable to all preterm and low birthweight babies. We limited data collection to what is currently routinely recorded. The next step would be to test the feasibility of replacing the current system of 
documenting vital signs with an EWS chart to explore if such tools can improve documentation without an unacceptable increase in workload. Further work is planned and will include emphasis on training for the use of EWSs.

Use of MOEWS in obstetrics in LMICs has highlighted the need of a 'partnership approach' and leadership from local teams. ${ }^{28}$ Our findings include the possibilities of resistance to change in keeping with the adoption theory, which proposes that any group consists of a mixture of 'innovators, early adopters, early majority, late majority, laggards' and resistance to change is expected. ${ }^{29}$ There are several steps outlined in innovation research that are transferable to this healthcare context; 'relative advantage', 'compatibility', 'complexity', 'trialability', 'observability'. ${ }^{29}$ In the context of implementing a neonatal EWS, emphasising relative advantage (eg, ease of use); ensuring that the new system 'fits' (compatibility); supporting with easily accessible training (complexity); having a period of trialling before implementing (trialability); and being clear to staff about any outcomes (observability) could facilitate adoption. The follow-up of implementation of MOEWS in Ethiopia showed that attitudes to new practice improved over time. ${ }^{28}$

\section{CONCLUSION}

Development of neonatal EWS in LMICs requires testing the acceptability and feasibility of recording vital signs using locally adapted neonatal EWS charts. Further work is required to ensure that such charts facilitate monitoring of vital signs without increasing workload. A partnership approach with local leadership and training programmes incorporating the principles of the adoption theory are vital. This preparatory work must precede any clinical trials investigating whether implementation of neonatal EWS could reduce neonatal mortality in LMICs.

\section{Author affiliations \\ ${ }^{1}$ Nottingham Clinical Trials Unit, School of Medicine, University of Nottingham \\ Faculty of Medicine and Health Sciences, Nottingham, UK \\ ${ }^{2}$ Department of Obstetrics and Gynaecology, University of Nairobi, Nairobi, Nairobi, \\ Kenya \\ ${ }^{3}$ Department of Paediatrics and Child Health, University of Nairobi, Nairobi, Nairobi, Kenya \\ ${ }^{4}$ Kenya Paediatric Research Consortium (KEPRECON), Nairobi, Kenya \\ ${ }^{5}$ School of Education, University of Nottingham, Nottingham, UK \\ ${ }^{6}$ School of Health Sciences, University of Nottingham, Nottingham, UK \\ ${ }^{7}$ Division of Graduate Entry Medicine, School of Medicine, University of Nottingham Faculty of Medicine and Health Sciences, Nottingham, UK \\ ${ }^{8}$ Neonatal Unit, University Hospitals of Derby and Burton NHS Foundation Trust, Derby, UK}

\section{Twitter Eleanor J Mitchell @eleanor_mitch}

Acknowledgements We would like to thank the team of research midwives at the Kenyatta National Hospital for their assistance in data collection. We also thank everyone who attended the networking event for their input. Thank you to staff at the Nottingham Clinical Trials Unit for their input: Lisa Evans and Charlotte Gidman (data management), Daniel Simpkins (database programming).

Contributors EJM was the overall principal investigator and conceived the idea and wrote the first draft of the manuscript. SO was the overall clinical lead. $\mathrm{ZPQ}$ was the principal investigator and J0 was the Study Coordinator in Kenya.
GG and $A 0$ provided obstetric expertise and facilitated data collection. FW was the lead neonatologist in Kenya. LB undertook statistical analyses. JD provided mentorship to the research group. PP provided midwifery expertise. M0 assisted with qualitative analysis. All authors contributed to the manuscript and approved the final draft.

Funding The observational study was funded by a Global Challenges Research Fund (GCRF) pump-priming grant by the University of Nottingham (ref RIS 630122). The stakeholder meeting was funded by an in-country networking event grant by the University of Nottingham (ref RIS 630131).

Competing interests None declared.

Patient consent for publication Not required.

Ethics approval The study was conducted with full ethical approval from the joint Kenyatta National Hospital-University of Nairobi Ethics Research Committee (ref P772/11/2018) and the Faculty of Medicine and Health Sciences Research Ethics Committee at the University of Nottingham (ref 161-1812).

Provenance and peer review Not commissioned; externally peer reviewed.

Data availability statement Data are available on reasonable request to the corresponding author.

Supplemental material This content has been supplied by the author(s). It has not been vetted by BMJ Publishing Group Limited (BMJ) and may not have been peer-reviewed. Any opinions or recommendations discussed are solely those of the author(s) and are not endorsed by BMJ. BMJ disclaims all liability and responsibility arising from any reliance placed on the content. Where the content includes any translated material, BMJ does not warrant the accuracy and reliability of the translations (including but not limited to local regulations, clinical guidelines, terminology, drug names and drug dosages), and is not responsible for any error and/or omissions arising from translation and adaptation or otherwise.

Open access This is an open access article distributed in accordance with the Creative Commons Attribution Non Commercial (CC BY-NC 4.0) license, which permits others to distribute, remix, adapt, build upon this work non-commercially, and license their derivative works on different terms, provided the original work is properly cited, appropriate credit is given, any changes made indicated, and the use is non-commercial. See: http://creativecommons.org/licenses/by-nc/4.0/.

\section{ORCID iDs}

Eleanor J Mitchell http://orcid.org/0000-0002-6998-4533

Shalini 0jha http://orcid.org/0000-0001-5668-4227

\section{REFERENCES}

1 Chawanpaiboon S, Vogel JP, Moller A-B, et al. Global, regional, and national estimates of levels of preterm birth in 2014: a systematic review and modelling analysis. Lancet Glob Health 2019;7:e37-46.

2 Blencowe $\mathrm{H}$, Cousens S, Oestergaard MZ, et al. National, regional, and worldwide estimates of preterm birth rates in the year 2010 with time trends since 1990 for selected countries: a systematic analysis and implications. Lancet 2012;379:2162-72.

3 World Health Organisation. Child causes of death 2000-2017. Available: https://www.who.int/healthinfo/global_burden_disease/ estimates/en/index2.html [Accessed 7 Feb 2020].

4 United Nations. UN sustainable development goals. Available: https://sustainabledevelopment.un.org/ [Accessed 14 Feb 2020].

5 UNICEF. UNICEF child mortality estimates: regional and global neonatal mortality rate. Available: http://data.unicef.org [Accessed 25 Jul 2019].

6 Republic of Kenya Ministry of Health. Basic paediatric protocol 4th edition 2016.

7 World Health Organisation. Pregnancy, childbirth, postpartum and newborn care: a guide for essential practice. 3rd edn, 2015.

8 World Health Organisation. WHO recommendations on interventions to improve preterm birth outcomes 2015.

9 Conde-Agudelo A, Díaz-Rossello JL. Kangaroo mother care to reduce morbidity and mortality in low birthweight infants. Cochrane Database Syst Rev 2016:CD002771.

10 World Health Organisation. Born too soon: the global action report on preterm birth 2012.

11 Gerry S, Birks J, Bonnici T, et al. Early warning scores for detecting deterioration in adult hospital patients: a systematic review protocol. BMJ Open 2017;7:e019268.

12 Mortensen N, Augustsson JH, Ulriksen J, et al. Early warning- and track and trigger systems for newborn infants: a review. J Child Health Care 2017;21:112-20. 
13 British Association of Perinatal Medicine. British association of perinatal medicine. newborn early warning trigger and track (NEWTT): a framework for practice. British association of perinatal medicine 2015;17.

14 Paliwoda M, New K, Bogossian F. Neonatal early warning tools for recognising and responding to clinical deterioration in neonates cared for in the maternity setting: a retrospective case-control study. Int J Nurs Stud 2016;61:125-35.

15 Merriel A, Murove BT, Merriel SWD, et al. Implementation of a modified obstetric early warning system to improve the quality of obstetric care in Zimbabwe. Int J Gynaecol Obstet 2017;136:175-9.

16 Braun V, Clarke V. Using thematic analysis in psychology. Qual Res Psychol 2006;3:77-101.

17 Roland DMJ, Connolly G. The newborn early warning (new) system: development of an at-risk infant intervention system. Infant 2010;6:116-20.

18 Ridde V. Need for more and better implementation science in global health. BMJ Glob Health 2016;1:e000115.

19 Murphy GAV, Omondi GB, Gathara D, et al. Expectations for nursing care in newborn units in Kenya: moving from implicit to explicit standards. BMJ Glob Health 2018;3:e000645.

20 Lawn JE, Cousens S, Zupan J. Lancet neonatal survival steering T. 4 million neonatal deaths: when? where? why? Lancet 2005;365:891-900.
21 Murphy GAV, Gathara D, Mwachiro J, et al. Effective coverage of essential inpatient care for small and sick newborns in a high mortality urban setting: a cross-sectional study in Nairobi City County, Kenya. BMC Med 2018;16:72.

22 Lawn JE, Mwansa-Kambafwile J, Horta BL, et al. 'Kangaroo mother care' to prevent neonatal deaths due to preterm birth complications. Int J Epidemiol 2010;39:i144-54.

23 World Health Organisation. Thermal protection of the newborn: a practical guide 1997

24 Lunze K, Bloom DE, Jamison DT, et al. The global burden of neonatal hypothermia: systematic review of a major challenge for newborn survival. BMC Med 2013;11:24.

25 Sodemann M, Nielsen J, Veirum J, et al. Hypothermia of newborns is associated with excess mortality in the first 2 months of life in Guinea-Bissau, West Africa. Trop Med Int Health 2008;13:980-6.

26 Aluvaala J, Nyamai R, Were F, et al. Assessment of neonatal care in clinical training facilities in Kenya. Arch Dis Child 2015;100:42-7.

27 Yoshida S, Martines J, Lawn JE, et al. Setting research priorities to improve global newborn health and prevent stillbirths by 2025 . $J$ Glob Health 2016;6:010508.

28 Moore J, Thomson D, Pimentil I, et al. Introduction of a modified obstetric early warning system -(-MOEWS-)- at an Ethiopian referral hospital: a feasibility assessment. BMJ Open Qual 2019;8:e000503.

29 Allen E. Diffusion of innovations. New York: Simon \& Schuster, 2003. 